\title{
Síncope e Alçamento da Vogal Postônica Não Final /o/: uma relação entre dois fenômenos variáveis
}

\author{
Syncope and Raising of the Postonic Non Final Vowel /o/: \\ A RELATIONSHIP BETWEEN TWO VARIABLE PHENOMENA
}

\section{Susiele MACHRY DA SILVA* Raquel Gomes CHAVES **}

Resumo: Neste estudo, analisamos de forma concomitante os processos fonológicos variáveis de síncope (abóbora abóbra) e de alçamento (abóbora abóbura) da vogal postônica não final /o/, a fim de estabelecer as possíveis relações entre os dois fenômenos e explicar quais motivações estruturais e/ou sociais poderiam explicar a escolha do falante por uma variante ou outra. A análise, conduzida com base nos pressupostos teóricos metodológicos da Teoria da Variação e Mudança (WEINREINCH; LABOV; HERZOG, 1968; LABOV, 1972, 1994, 2001), leva em conta a fala de 14 sujeitos oriundos da comunidade de Rincão Vermelho-RS - dados que compõem a amostra complementar VARSUL, agência PUCRS. Os resultados sugerem que, relacionados à atuação dos fatores linguísticos, os dois processos manifestam-se nos mesmos ambientes; não obstante, observamos o papel do léxico e dos fatores extralinguísticos, mais precisamente o nível de escolaridade, como significativos na aplicação de ambos os processos. Além disso, a partir da aplicação do teste de correlação Kendall Tau, verificamos uma correlação negativa entre os fenômenos investigados.

\footnotetext{
* Doutora em Letras pela Pontifícia Universidade Católica do Rio Grande do Sul (2014). Professora Assistente da Universidade Católica de Pelotas - UCPEL. Contato: susiele@bol.com.br.

** Doutoranda em Linguística pela Universidade Federal de Santa Catarina (UFSC). Contato:quelgchaves@gmail.com.
} 
Palavras-chave: Síncope. Alçamento. Vogal postônica não final /o/.

Abstract: In this paper, we analyzed concomitantly two variable phonological processes, syncope (abóbora abobra) and raising (abóbora $\sim$ abóbura) of the postonic non final vowel /o/, in order to establish the possible relationship between these two phenomena, and also to explain the social and/or structural factors that could explain the choice of the speaker by a variant or another. This analysis, conducted based on theoretical and methodological assumptions of the Theory of Variation and Change (WEINREINCH; LABOV; HERZOG, 1968; LABOV, 1972, 1994, 2001), takes into account the speech of 14 individuals from Rincão Vermelho - RS - data that constitute the complementary sample of VARSUL database, PUCRS agency. The results suggest that, related to the action of linguistic factors, both processes were verified in the same environments; however, we observed the role of lexical and extralinguistic factors, more specifically the Educational Level, as significant in the application of both processes. Furthermore, after the application of Kendall Tau correlation test, we found a negative correlation between phenomena investigated.

Keywords: Syncope. Uprising. Non final postonic vowel /o/.

\section{Introdução}

Estudos sociolinguísticos brasileiros, enquadrados na perspectiva laboviana, têm se dedicado, tradicionalmente, à análise de fenômenos variáveis isolados. Em outros termos, as pesquisas realizadas no Brasil, empreendidas dentro desse quadro teórico-metodológico, em geral, investigam a ação de variáveis independentes linguísticas e extralinguísticas sobre um único processo variável. Desse modo, verifica-se, na área, carência de estudos que busquem estabelecer relações entre fenômenos variáveis distintos.

Nesse sentido, Guy (2013) atenta para o fato de que, para que se possa delinear os usos linguísticos de uma determinada variedade, é necessário pensar na relação existente entre diversos fenômenos em variação. $\mathrm{O}$ autor usa o termo "coerência social" (social coherence) para se referir ao fato de que 
esperaríamos que, na variedade culta de uma determinada língua, por exemplo, algumas variáveis linguísticas, principalmente aquelas que têm se mostrado sensíveis ao prestígio, estivessem associadas. $\mathrm{O}$ autor mostra, por exemplo, após análise de dados da fala carioca, uma correlação positiva entre os índices de concordância verbal $(\mathrm{CV})$ e concordância nominal $(\mathrm{CN})$ na variedade de sujeitos com alto grau de instrução: quanto maior o índice de $\mathrm{CV}$, maior também o índice de $\mathrm{CN}$.

Assim sendo, conforme salientado por Guy (2013), é necessário, apesar de pouco frequente, tratar do problema do encaixamento (WEINREINCH; LABOV; HERZOG, 1968; LABOV, 1994), observando, na variedade em estudo, além da covariação entre as variáveis independentes (linguísticas e extralinguísticas) e o fenômeno variável em exame, a correlação entre diferentes fenômenos variáveis. Nas palavras do autor: "tais variedades sociais reificadas necessariamente englobam múltiplas variáveis sociolinguísticas” (GUY, 2013, p. 1, tradução nossa) ${ }^{1}$. Desse modo, Guy (2013, p. 2, tradução nossa) assume que "Se variedades sociais têm uma coerência semelhante, as variáveis que as caracterizam devem apresentar algum tipo de força de vínculo, um padrão de correlação ou o uso [de fenômenos variáveis] em agrupamentos". ${ }^{2}$

Partindo dessa reflexão, propomos, neste estudo, aprofundar uma análise prévia (CHAVES; MACHRY DA SILVA, no prelo) de dois fenômenos linguísticos em variação no português brasileiro que atuam sobre a vogal postônica não final /o/: a sincope (árvore árvre) e o alçamento (árvore árvure). Primeiramente, assim como os estudos variacionistas clássicos, examinamos os processos independentemente, a fim de identificar os condicionadores de natureza linguística e extralinguística que atuam como colaboradores da manifestação de cada um dos fenômenos em exame. Após essa etapa, buscamos, a fim de promover uma discussão sobre o problema do encaixamento (WEINREICH; LABOV; HERZOG, 1968; LABOV, 1972, 1994, 2001, 2010), verificar se há alguma relação entre os fenômenos em análise, fazendo uso do teste de correlação Kendall Tau.

${ }^{1}$ No original: "The issue that I focus on here is that such reified social varieties will necessarily encompass multiple sociolinguistic variables."

${ }^{2}$ No original: "If social varieties have a similar coherence, the variables that characterize them should exhibit some kind of binding force, a pattern of correlation or clustered usage." 
Este estudo tem como objetivo analisar dois fenômenos fonológicos: sincope e alçamento da vogal /o/ em posição postônica não final. A partir desse objetivo geral, estipulamos três outros objetivos específicos: (i) verificar, na comunidade em estudo, com base nas variáveis independentes linguísticas apontadas como favorecedoras à aplicação dos fenômenos, os fatores que atuam de forma mais significativa na aplicação de cada um; (ii) avaliar qual o papel desempenhado pelas variáveis independentes extralinguísticas na aplicação dos processos; e (iii) observar se há uma correlação positiva ou negativa na aplicação da síncope e do alçamento, com vistas a discutir o problema do encaixamento (WEINREINCH; LABOV; HERZOG, 1968; LABOV, 1972, 1994, 2001, 2010).

Apresentado o mote deste artigo, expomos, a seguir, sua organização. $\mathrm{Na}$ seção 1, apresentamos uma breve revisão de literatura de ambos os processos investigados (síncope e alçamento). Na seção 2, tratamos dos procedimentos metodológicos empregados. $\mathrm{Na}$ seção 3, divulgamos os resultados e, por fim, exibimos as considerações finais a respeito dos resultados atingidos.

\section{Breve Revisão de Literatura}

Estudos centrados na investigação da síncope da vogal postônica não final em dados de fala do PB (AMARAL, 1999; SILVA, 2006; LIMA, 2008; RAMOS, 2009; CHAVES, 2011) apresentam concordância praticamente plena em relação aos condicionadores linguísticos do processo: (i) consoantes líquidas (lateral e vibrante) em contexto seguinte à vogal (óculos $\sim$ óclos, árvore a árvre); (ii) consoantes labiais e velares, em contato precedente à vogal postônica (abóbora abóbra, xícara xícra); (iii) vogal dorsal /a/ e vogais labiais $/ \mathrm{o} / \mathrm{e} / \mathrm{u} /($ chácara $\sim$ chácra, cócoras $\sim$ cócras, óculos $\sim$ óclos $)$. Em relação aos condicionadores extralinguísticos, observa-se, também, consenso entre os resultados divulgados: (i) a variável Escolaridade foi apontada pelos trabalhos de Amaral (1999), Silva (2006) e Lima (2008) como relevante à aplicação do processo, sendo os informantes com menor grau de instrução responsáveis pela produção mais expressiva de síncope.

Já as pesquisas que trataram do alçamento da vogal postônica não final em dados de fala coletados no Rio Grande do Sul (SCHIMITT, 1987; 
VIEIRA, 1994, 2002; MACHRY DA SILVA, 2009), embora os grupos de fatores controlados apresentem diferença entre os autores, apontam conformidade quanto à força de alguns condicionadores linguísticos sobre o processo de alçamento da vogal /o/3: (i) obstruintes labiais e velares, em contexto precedente (fósforo $\sim$ fósfuro, brócolis $\sim$ bróculis); (ii) consoantes labiais e consoantes líquidas, em contexto seguinte (boróscopo $\sim$ horóscupo, brócolis $\sim$ bróculis); (iii) presença de vogal alta na sílaba tônica (idolo $\sim$ idulo). No que diz respeito aos condicionadores sociais, é possível apontar o papel favorecedor da variável Escolaridade, sendo os informantes com maior grau de instrução os que tendem a elevar a vogal com maior frequência.

É possível depreender, nesse sentido, uma tendência apontada pelos estudos sobre os fenômenos de síncope e alçamento da vogal postônica não final /o/: (i) as consoantes labiais e velares, em contexto precedente, são apontadas como favorecedoras tanto da síncope quanto do alçamento; (ii) as consoantes líquidas em posição seguinte à vogal também são indicadas como relevantes à manifestação dos processos; e (iii) a variável Escolaridade é referida como significativa à atuação de ambos os fenômenos.

Vale destacar que as hipóteses quanto ao papel da variável Escolaridade na manifestação dos processos de síncope e alçamento são corroboradas pelo estudo de Chaves e Machry da Silva (no prelo). Ao investigar o papel dos fatores sociais que atuariam de forma favorável à incidência dos processos de síncope e alçamento na comunidade de Rincão Vermelho, no Rio Grande do Sul, as autoras concluem que a escolaridade dos falantes desempenha papel significativo na aplicação dos dois fenômenos. No entanto, foi observado que a variável atua de forma diferenciada em cada processo: falantes com maior nível de escolaridade optam, em geral, pelo alçamento, e falantes com menor nível de escolaridade, pela síncope. Ou seja, à medida que o grau de instrução dos sujeitos aumenta, verifica-se a diminuição da produção de síncope e, em contrapartida, o aumento da produção de alçamento.

${ }^{3}$ Visto que poucos são os dados retratados pela literatura de alçamento da vogal /e/ em posição postônica não final (número númiro, pêssego pêssigo), analisaremos aqui apenas as proparoxítonas com vogal postônica /o/. 


\section{Procedimentos Metodológicos}

O estudo aqui proposto, vinculado à Teria da Variação (WEINREINCH; LABOV; HERZOG, 1968; LABOV, 1972, 1994, 2001, 2010), propõe uma reanálise, pautada em uma inspeção acústica dos dados, do trabalho de Chaves e Machry da Silva (no prelo) ${ }^{4}$, com vistas a relacionar os processos de alçamento e de síncope da vogal média /o/ não final. A análise foi desenvolvida a partir da mesma amostra de dados considerada pelas autoras, constituída por 14 entrevistas integrantes da amostra complementar - Machry da Silva (2009) - do banco de dados VARSUL ${ }^{5}$, agência PUCRS. Os dados são provenientes de falantes da comunidade rural de Rincão Vermelho-RS, situada na fronteira do Brasil com a Argentina. Para a composição da amostra, os sujeitos foram estratificados levando-se em conta as características sociais escolaridade, sexo e idade. A estratificação dos informantes, nas respectivas células sociais, encontra-se disposta no Quadro 1, a seguir.

Quadro 1 - Distribuição dos informantes por célula

\begin{tabular}{|c|c|c|c|c|c|c|}
\hline & \multicolumn{3}{|c|}{ Sexo Feminino } & \multicolumn{3}{c|}{ Sexo Masculino } \\
\cline { 2 - 7 } & $\begin{array}{c}\mathbf{1 5} \mathbf{a} \\
\mathbf{3 5}\end{array}$ & $\begin{array}{c}\mathbf{3 6} \mathbf{a} \\
\mathbf{5 7}\end{array}$ & $\begin{array}{c}\mathbf{5 8} \text { ou } \\
+\end{array}$ & $\begin{array}{c}\mathbf{1 5} \mathbf{a} \\
\mathbf{3 5}\end{array}$ & $\begin{array}{c}\mathbf{3 6} \mathbf{a} \\
\mathbf{5 7}\end{array}$ & $\begin{array}{c}\mathbf{5 8} \text { ou } \\
+\end{array}$ \\
\hline $\begin{array}{c}\text { Ensino } \\
\text { Fundamental }\end{array}$ & 1 & 1 & 1 & 1 & 1 & 1 \\
\hline $\begin{array}{c}\text { Ensino } \\
\text { Médio }\end{array}$ & 1 & 1 & 1 & 1 & 1 & 1 \\
\hline $\begin{array}{c}\text { Ensino } \\
\text { Superior }\end{array}$ & 1 & 0 & 0 & 1 & 0 & 0 \\
\hline
\end{tabular}

Fonte: Adaptado de Machry da Silva (2009)

Para que fossem incluídos no universo amostral investigado, esses informantes deveriam: (i) ser nativos da comunidade ou nela estar residindo

${ }^{4}$ No estudo de Chaves e Machry da Silva, a análise foi conduzida com base somente em uma investigação de oitiva de ambos os processos.

${ }^{5}$ Projeto Variação Linguística Urbana na Região Sul. 
pelo menos $2 / 3$ de suas vidas; e (ii) ser falantes monolíngues do português, sem ter se ausentado da comunidade por mais de seis meses anteriores à data da coleta. Ao serem contatados, os sujeitos eram informados dos objetivos da pesquisa, e os que estavam de pleno acordo, assinaram um Termo de Consentimento Livre e Esclarecido. Antes da realização das entrevistas, os informantes foram também convidados a preencher uma ficha social, com informações referentes às características indexicais (sexo, idade, escolaridade, entre outras) e sociais, tais como o contato com o espanhol, com a variedade fronteiriça e com os centros urbanos próximos à comunidade. Em seguida, foi realizada, com cada participante, uma entrevista pessoal que versava sobre assuntos da infância, comunidade, interesses, projetos futuros, entre outros temas. Além dessa entrevista, os informantes responderam oralmente a um questionário, aplicado com a finalidade de induzir a produção de proparoxítonas, as quais são pouco recorrentes na fala casual. Nesse caso, foram selecionadas imagens de 12 proparoxítonas, contendo a vogal média /o/ em sílaba postônica não final. Ao ouvir a questão (ex.: Tipo de verdura plantada na horta? Resposta: brócolis, por exemplo), o informante tinha a oportunidade de visualizar a imagem antes de dar sua resposta.

\subsection{Variáveis operacionais}

Em um primeiro momento, efetuamos duas análises: uma centrada no fenômeno de síncope e outra, no de alçamento. As variantes consideradas em cada uma das rodadas encontram-se expostas no quadro seguinte.

Quadro 2 - Fenômenos variáveis em exame

\begin{tabular}{|ll|ll|}
\hline \multicolumn{1}{|c|}{ Variável 1 } & \multicolumn{1}{c|}{ Variável 2 } \\
\hline a) Síncope (abóbra) & a) & alçamento (abóbura $)$ \\
b) manutenção da vogal [o] & b) & síncope ou manutenção da \\
& & vogal [o] \\
& ou [u] & & $($ abóbora $/$ abóbra $)$ \\
\hline
\end{tabular}

Fonte: As autoras 
Conduzimos a análise estatística dos fenômenos levando em conta as variáveis independentes linguísticas apontadas como relevantes pelos estudos sociolinguísticos sobre o alçamento e a síncope no PB (Cf. Seção 1). Incluímos, entretanto, neste estudo a análise da frequência do item lexical na língua, variável não observada pelos estudos anteriores, com vistas a verificar o possível papel do léxico, quanto à frequência, na ocorrência dos processos de alçamento ou de síncope da vogal /o/. As variáveis linguísticas contempladas neste trabalho encontram-se elencadas no Quadro 3, a seguir:

Quadro 3 - Variáveis independentes linguísticas

\begin{tabular}{|c|c|c|}
\hline \multicolumn{3}{|c|}{ Síncope e Alçamento } \\
\hline $\begin{array}{l}\text { Contexto } \\
\text { Fonológico } \\
\text { Precedente }\end{array}$ & $\begin{array}{l}\text { velar } \\
\text { labial } \\
\text { coronal }\end{array}$ & $\begin{array}{l}\text { cócoras } \\
\text { abóbora } \\
\text { método }\end{array}$ \\
\hline $\begin{array}{l}\text { Contexto } \\
\text { Fonológico } \\
\text { Precedente } \\
\end{array}$ & $\begin{array}{l}\text { oclusivo e nasal } \\
\text { líquido }\end{array}$ & $\begin{array}{l}\text { psicóloga, } \\
\text { agrônomo } \\
\text { pérula }\end{array}$ \\
\hline Item Lexical & $\begin{array}{l}\text { itens lexicais mais recorrentes na } \\
\text { amostra }\end{array}$ & $\begin{array}{l}\text { pérola } \\
\text { abóbora } \\
\text { cócoras }\end{array}$ \\
\hline $\begin{array}{l}\text { Frequência do } \\
\text { Item Lexical }\end{array}$ & $\begin{array}{l}\text { frequência da palavra - extraída do } \\
\text { corpus do Português Brasileiro } \\
\text { LAEL-PUCSP } \\
\text { (variável contínua) }\end{array}$ & \\
\hline
\end{tabular}

Fonte: As autoras

De acordo com os resultados apresentados pelos estudos prévios (Cf. Seção 1), partimos da hipótese de que os contextos linguísticos que favorecem a aplicação da síncope e do alçamento tendem a ser praticamente os mesmos, preservada a especificidade de cada regra. A partir dessa observação, inferimos que a escolha do falante pelo alçamento, pela síncope 
ou pela preservação da vogal /o/pode estar relacionada com a atuação dos fatores de ordem social. Para refutar/corroborar essa hipótese, além das variáveis linguísticas, este estudo investiga a atuação das variáveis sociais Sexo, Faixa Etária e Escolaridade, variáveis delimitadas com base na estratificação de Machry da Silva (2009). No Quadro 4, a seguir, apresentamos uma tabela sistemática das variáveis extralinguísticas controladas neste estudo.

Quadro 4 - Variável independentes extralinguísticas

\begin{tabular}{|c|c|}
\hline \multicolumn{2}{|c|}{ Síncope e Alçamento } \\
\hline Sexo & $\begin{array}{l}\text { feminino } \\
\text { masculino }\end{array}$ \\
\hline Faixa Etária & $\begin{array}{l}\text { entre } 15 \text { e } 35 \text { anos } \\
\text { entre } 36 \text { e } 57 \text { anos } \\
\text { acima de } 57 \text { anos }\end{array}$ \\
\hline Escolaridade & $\begin{array}{l}\text { Ensino Fundamental (EF) } \\
\text { Ensino Médio (EM) } \\
\text { Ensino Superior (ES) }\end{array}$ \\
\hline
\end{tabular}

Fonte: Adaptado de Machry da Siva (2009)

A hipótese aventada quanto ao papel das variáveis sociais, elaborada com base em estudos anteriores (MACHRY DA SILVA, 2009; CHAVES, 2011; CHAVES; MACHRY DA SILVA, no prelo), é a de que principalmente a variável Escolaridade desempenha um forte papel na escolha de uma forma linguística em detrimento das demais, visto que os contextos linguísticos "preferidos" pela aplicação de ambas as regras parecem ser, conforme exposto, praticamente os mesmos. Nesse sentido, os informantes mais escolarizados, segundo nossa conjectura, optariam pelo alçamento com maior frequência e, por outro lado, informantes menos escolarizados tenderiam a realizar em maior grau a síncope, o que sugere uma correlação negativa entre ambos os fenômenos, se levarmos em conta essa dimensão de análise. 


\subsection{Procedimentos de análise dos dados}

A análise dos dados, a ser apresentada nas seções subsequentes, foi realizada a partir do programa estatístico Rbrul, desenvolvido por Daniel Johnson (2009), o qual se destina à análise de dados linguísticos por regressão logística, à semelhança dos programas de análise quantitativa Varbrul2S (SANKOFF, 1975) e GoldvarbX (SANKOFF; TAGLIAMONTE; SMITH, 2005). O Rbrul mostra-se adequado para análise desenvolvida neste estudo por suas vantagens quanto à possibilidade de trabalhar com grupos de fatores de efeito aleatório, a exemplo do Item Lexical, o que permite verificar o papel do léxico nos processos, sem deixar de testar conjuntamente o peso das outras variáveis linguísticas e extralinguísticas. Além disso, a vantagem do Rbrul para este estudo justifica-se pela sua adequação a pesquisas com pouco número de dados, como é o caso das proparoxítonas, que por serem pouco recorrentes na língua, resultam em um número reduzido de dados para as análises.

Em linhas gerais, o Rbrul faz o reconhecimento e a interação de todos os grupos de fatores envolvidos e oferece resultados em termos de peso relativo e $\log$-odds. Considera-se que o $\log$-odd positivo e o peso relativo acima de 0,50 indicam favorecimento de um fator para aplicação do processo, enquanto o $\log$-odd negativo e o peso relativo inferior a 0,50 indicam não favorecimento. Quando o log-odd é de zero (0) e o peso relativo é de 0,50, a interpretação é a de que há um efeito neutro do fator.

Dadas as especificidades da condução da análise, na próxima seção, apresentamos os resultados obtidos e a discussão quanto à relação dos processos de síncope e alçamento em proparoxítonas com vogal média /o/ em posição postônica não final.

\section{Análise e Discussão dos Resultados}

Conforme já havíamos pontuado anteriormente, o grupo de palavras proparoxítonas trata-se de um grupo limitado no léxico do português, língua que tem como default o padrão paroxítono. Desse modo, ao delimitarmos como objeto de investigação apenas as proparoxítonas com vogal postônica não final /o/, reduzimos ainda mais o número de dados passíveis de 
investigação. De forma mais específica, apesar de termos considerado 14 entrevistas de fala semiespontânea e 14 questionários lexicais, obtivemos um total de apenas 269 dados que obedeciam aos critérios previamente estipulados. Desse total de dados, poucos são provenientes das entrevistas, nas quais os informantes produziram um baixo número de proparoxítonas. Desse modo, já que a maioria dos dados provém do questionário lexical, a análise do papel de variáveis linguísticas contextuais, tais como o Contexto Precedente e o Contexto Seguinte, torna-se, em parte, comprometida. Isso porque, como a maior parte dos dados investigados provém do questionário aplicado, os informantes produziram praticamente as mesmas palavras e, como consequência, os mesmos contextos se mostraram presentes. Essa constatação foi confirmada pela observação dos Crosstabs: verificamos alta ocorrência de células vazias e concentração de dados somente em determinados ambientes.

Do total de 269 dados, correspondentes a proparoxítonas com vogal postônica não final /o/, observamos, após inspeção acústica ${ }^{6}$, uma alta aplicação do processo de alçamento no item lexical "época" (item registrado em 91 ocorrências da amostra e com verificação de alçamento em 89 destas). A aplicação de forma praticamente categórica de alçamento nesse único item lexical influencia diretamente os resultados obtidos. Optamos, portanto, por excluir esses dados de nossa análise.

Após a exclusão dos dados relativos ao item lexical época, obtivemos os seguintes índices de aplicação dos processos de síncope e de alçamento, assim como os de manutenção da vogal referida.

Conforme mostra o Gráfico 1, a seguir, a preservação da vogal /o/ (árvore) foi observada em cerca de $20 \%$ dos dados (69/178). Entretanto, na maior parte dos dados em análise, a vogal postônica não final /o/ sofreu a ação de algum processo: em 41\% (74/178) das proparoxítonas, a vogal /o/ foi alçada a /u/ (psicoluga) e, em 20\% (35/178), a vogal foi elidida (abóbra). Essa análise inicial aponta a tendência dos informantes a optarem,

\footnotetext{
${ }^{6}$ A inspeção acústica empreendida neste estudo teve como objetivo auxiliar no trabalho de oitiva, de modo a identificar a presença/ausência da vogal (síncope ou manutenção) e suas características em temos de altura - F1 (alçamento ou manutenção). Nosso objetivo, entretanto, não foi o de realizar uma análise acústica detalhada.
} 
com mais frequência, pela preservação vocálica - seja pelo processo de manutenção da vogal ou por seu alçamento - do que pela sua elisão/síncope.

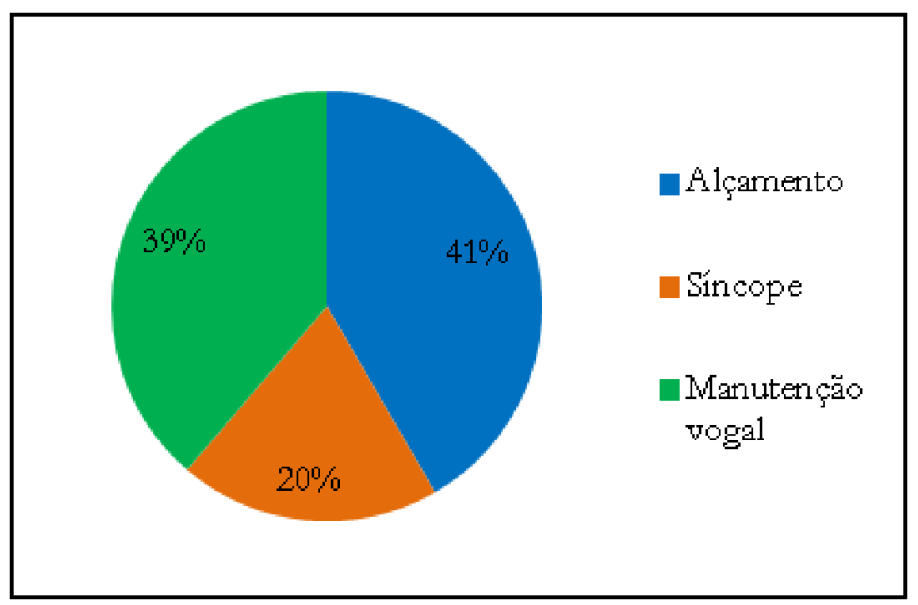

Fonte: As autoras

Gráfico 1 - Índice percentual de aplicação dos processos de síncope, alçamento e manutenção da vogal postônica não final /o/

\subsection{As variáveis independentes linguísticas e os processos de síncope e alçamento}

Conforme relatado no início desta seção, o pequeno número de dados que compõe a amostra de proparoxítonas (total de 178) dificultou a operacionalização estatística para a análise das variáveis linguísticas. Dentre as variáveis controladas (Cf. Seção 2.1), o programa Rbrul selecionou como estatisticamente relevantes as variáveis Item Lexical e Escolaridade, tanto para a síncope quanto para o alçamento. Em nenhuma das rodadas a que se procedeu houve a seleção das variáveis Contexto Precedente e Contexto Seguinte. Dessa forma, a fim de verificarmos em quais contextos a ocorrência de síncope e de alçamento se mostraria mais significativa, realizou-se o cruzamento de cada processo com as variáveis Contexto Precedente e Contexto Seguinte. A distribuição das ocorrências em termos de aplicação e não aplicação, bem como o percentual obtido, considerando os fatores amalgamados, encontram-se elencados no Quadro 5, a seguir. 
Quadro 5 - Contexto Precedente versus Alçamento e Síncope

\begin{tabular}{|c|c|c|c|c|}
\hline \multicolumn{5}{|c|}{ Contexto Precedente e Alçamento } \\
\hline Fator & $\begin{array}{c}\text { Total de } \\
\text { tokens }\end{array}$ & Aplicação & $\begin{array}{c}\text { Não } \\
\text { Aplicação }\end{array}$ & $\begin{array}{c}(\%) \\
\text { Aplicação }\end{array}$ \\
\hline labial (árvore, abóbora) & 85 & 26 & 59 & $30 \%$ \\
\hline velar (agrícola, brócolis) & 56 & 30 & 26 & $54 \%$ \\
\hline $\begin{array}{l}\text { coronal }+ \text { anterior } \\
\quad(\text { idolo, pérola })\end{array}$ & 37 & 18 & 19 & $48 \%$ \\
\hline \multicolumn{5}{|c|}{ Contexto Precedente e Síncope } \\
\hline Fator & $\begin{array}{c}\text { Total de } \\
\text { tokens }\end{array}$ & Aplicação & $\begin{array}{c}\text { Não } \\
\text { Aplicação }\end{array}$ & $\begin{array}{c}(\%) \\
\text { Aplicação }\end{array}$ \\
\hline labial (árvore, abóbora) & 85 & 24 & 61 & $28 \%$ \\
\hline velar (agricola, brócolis) & 56 & 11 & 45 & $19 \%$ \\
\hline $\begin{array}{c}\text { coronal }+ \text { anterior } \\
(\text { idolo, pérola })\end{array}$ & 37 & 1 & 36 & $2 \%$ \\
\hline & & & & \\
\hline
\end{tabular}

Fonte: As autoras

De acordo com os resultados descritos no Quadro 5, o processo de alçamento mostrou-se mais produtivo quando a consoante precedente à vogal /o/ era uma velar (brócolis, agrícola), com índice de aplicação de 54\%. Em segundo, podemos apontar como favorável ao alçamento as consoantes coronais + anteriores (pérola, ídolo), com aplicação de 48\%. As labiais, por sua vez, são as que menos favorecem o alçamento da vogal, com $30 \%$ de aplicação, o que indica que o alçamento de /o/ é menos recorrente em formas como cômoda e abóbora, por exemplo.

Com relação ao Contexto Precedente e o processo de síncope, as consoantes labiais (abóbora, fósforo) aparecem em primeiro lugar, com aplicação de 28\%; as consoantes velares (cócoras, brócolis) aparecem na segunda posição, com 19\% de aplicação; enquanto as coronais + anteriores situam-se na última posição, com apenas $2 \%$ de aplicação; ou seja, não há tendência à realização de síncope em dados como pérola e ídolo, por exemplo. 
Os mesmos procedimentos de análise desenvolvidos para a variável Contexto Precedente foram aplicados para a variável Contexto Seguinte. Procedemos, dessa forma, ao cruzamento de ambos os fenômenos com o ambiente subsequente à vogal. Nesse caso, entretanto, optamos por analisar separadamente as consoantes líquidas $/ 1 / \mathrm{e} / \mathrm{r} /$ das demais consoantes coronais, o que se explica pela alta recorrência apresentada por esses contextos na amostra investigada. Os resultados, considerando os fatores amalgamados, são apresentados no Quadro 6, a seguir.

Quadro 6 - Contexto Seguinte versus Alçamento e Síncope

\begin{tabular}{|c|c|c|c|c|}
\hline \multicolumn{5}{|c|}{ Contexto Seguinte e Alçamento } \\
\hline Fator & $\begin{array}{c}\text { Total } \\
\text { de } \\
\text { tokens }\end{array}$ & Aplicação & $\begin{array}{c}\text { Não } \\
\text { Aplicação }\end{array}$ & $\begin{array}{c}(\%) \\
\text { Aplicação }\end{array}$ \\
\hline $\begin{array}{l}\text { coronal }+ \text { anterior } \\
(\text { método, cômoda })\end{array}$ & 17 & 2 & 15 & $12 \%$ \\
\hline líquida (agrícola, fósforo) & 141 & 68 & 73 & $48 \%$ \\
\hline $\begin{array}{c}\text { labial } \\
\text { (horóscopo, ecônomico) }\end{array}$ & 11 & 4 & 7 & $36 \%$ \\
\hline velares (psicólogo) & 9 & 1 & 9 & $11 \%$ \\
\hline \multicolumn{5}{|c|}{ Contexto Seguinte e Síncope } \\
\hline Fator & $\begin{array}{c}\text { Total } \\
\text { de } \\
\text { tokens }\end{array}$ & Aplicação & $\begin{array}{c}\text { Não } \\
\text { Aplicação }\end{array}$ & $\begin{array}{c}(\%) \\
\text { Aplicação }\end{array}$ \\
\hline $\begin{array}{c}\text { coronal }+ \text { anteriores } \\
(\text { método, cômoda })\end{array}$ & 17 & 0 & 17 & $0 \%$ \\
\hline líquida (agrícola, fósforo) & 141 & 34 & 107 & $24 \%$ \\
\hline $\begin{array}{c}\text { labial } \\
\text { (boróscopo, ecônomico) }\end{array}$ & 11 & 1 & 10 & $0,09 \%$ \\
\hline velar (psicólogo) & 9 & 0 & 9 & $0 \%$ \\
\hline
\end{tabular}

Fonte: As autoras 
Os dados expostos no Quadro 6 revelam que o alçamento ocorre em maior frequência quando o contexto seguinte é uma consoante líquida (agricola, fósforo), com 48\% de aplicação. As consoantes labiais em formas como horóscopo e ecônomo, com 36\% de aplicação, encontram-se na segunda posição. Os contextos com coronais + anteriores (método) e velares (psicólogo), com $12 \%$ e $11 \%$ de aplicação, respectivamente, são os que apresentam menos ocorrências de alçamento.

Em conformidade com os resultados obtidos para o alçamento, observamos que a síncope, embora tenha apresentado baixa aplicação em todos os contextos, tende a ocorrer, em maior proporção, quando a consoante seguinte é uma líquida (fósforo, agrícola), com $24 \%$ de aplicação. As consoantes labiais, velares e coronais + anteriores se mostram inibidoras do processo, demonstrando que não há tendência à manifestação de síncope em formas como horóscopo, psicólogo e cômoda, por exemplo.

Os resultados quanto ao contexto circundante mostram que, mesmo que seja possível observar a preferência pela síncope ou pelo alçamento, a depender do contexto, há certa conformidade quanto à ocorrência dos processos, de forma que as consoantes que favorecem o alçamento se apresentam atuantes também para a síncope. Nesse sentido, quanto ao Contexto Precedente, por exemplo, a síncope e o alçamento tendem a se manifestar quando se tem uma consoante velar ou uma consoante labial. Já as consoantes coronais + anteriores favorecem mais o alçamento do que síncope. Em relação ao Contexto Seguinte, a análise revela que tanto o processo de síncope quanto o processo de alçamento da vogal tendem a sofrer influência das consoantes líquidas $/ 1 / \mathrm{e} / \mathrm{r} /$.

A revelação de que há certa conformidade quanto aos contextos linguísticos que condicionam os processos de síncope e alçamento nos conduziu ao entendimento de que a relação entre os dois processos e o contexto circundante, precedente ou seguinte, tem pouco papel. Em outros termos, a opção do falante pela síncope ou pelo alçamento parece não estar relacionada aos contextos anteriores e subsequentes, já que ambos os processos mostraram-se condicionados, em muitos casos, pelos mesmos fatores. Supomos, então, que outras variáveis poderiam estar influenciando na escolha do falante. Dado o reduzido número de dados e a recorrência de um limitado número de itens lexicais no corpus, optamos por observar o comportamento 
dos fenômenos a partir da variável Item Lexical, nesse caso, considerada como variável aleatória. Nas duas rodadas realizadas, avaliando separadamente a ocorrência de cada processo, a variável foi selecionada como estatisticamente significativa. Os resultados em percentuais, pesos relativos e log-odds, para os itens lexicais mais recorrentes na amostra, são apresentados na Tabela 1.

Os dados expostos na tabela anterior permitem verificar que há preferência pelo alçamento da vogal /o/ nos itens lexicais agrícola, brócolis, idolo, simbolo, árvore e fósforo, os quais apresentam log-odds positivos e peso relativo acima de 0,5. Por outro lado, os itens lexicais horóscopo, abóbora, cócoras e cômoda, com peso relativo igual ou inferior a 0,5 , são os que apresentam menor tendência à manifestação do alçamento. A preferência pelo alçamento em relação à síncope e à preservação em dados como agrícola, ídolo e símbolo, estruturalmente, pode ser explicada pela presença da vogal alta na sílaba tônica. Nesse caso, segundo Vieira (2002, p. 147), estaríamos diante de um processo assimilatório, no qual o traço de altura da vogal alta precedente espraia para a vogal não final, tornando-a alta.

Com relação à síncope, notamos que o processo ocorre de forma mais recorrente nas formas abóbora, fósforo, cócoras, brócolis e árvore, em que se verifica $\log$-odds positivos e pesos relativos acima de 0,5 . Os itens lexicais pérola, ídolo, cômoda, agrícola e símbolo, por sua vez, são os que apresentam menor incidência da síncope, com peso relativo inferior a 0,5. Formas como horóscopo e cômoda mostram preferência pela preservação da vogal, ou seja, nesses casos, não verificamos tendência de aplicação dos processos de síncope e de alçamento.

Diante dos resultados, é possível inferir que, a depender do item lexical, a preferência será pela síncope, pelo alçamento ou pela preservação da vogal. A manifestação dos processos, nesse sentido, parece acontecer de forma independente, se observarmos que os itens lexicais que tendem a apresentar maiores índices de alçamento, a exemplo de agrícola, idolo, símbolo, pérola, são os que apresentam menor manifestação de síncope. De forma análoga, os itens lexicais que apresentam maior ocorrência de síncope são os que apresentam menor incidência de alçamento, a exemplo de cócoras e abóbora. Já em formas como fósforo e brócolis, se verifica a preferência pela síncope, embora tenhamos observado alguns casos de alçamento. 
Tabela 1 - Item Lexical versus Alçamento e Síncope

\section{Alçamento}

\begin{tabular}{|c|c|c|c|c|}
\hline Palavra & $\begin{array}{l}\text { Frequência } \\
\text { de } \\
\text { ocorrência }\end{array}$ & $\begin{array}{c}\text { Percentual } \\
\text { de } \\
\text { aplicação }\end{array}$ & $\begin{array}{c}\text { Peso } \\
\text { Relativo }\end{array}$ & Log-Odds \\
\hline Agrícola & 56.420 & $83 \%$ & 0,87 & 1,96 \\
\hline Brócolis & 664 & $67 \%$ & 0,79 & 1,40 \\
\hline Ídolo & 3.980 & $67 \%$ & 0,77 & 1,29 \\
\hline Pérola & 585 & $67 \%$ & 0,75 & 1,19 \\
\hline Símbolo & 788 & $57 \%$ & 0,71 & 0,94 \\
\hline Árvore & 18.569 & $45 \%$ & 0,60 & 0,48 \\
\hline Fósforo & 3.203 & $42 \%$ & 0,57 & 0,36 \\
\hline Horóscopo & 132 & $40 \%$ & 0,50 & 0,06 \\
\hline Abóbora & 2.360 & $13 \%$ & 0,27 & $-0,92$ \\
\hline Cócoras & 38 & $0 \%$ & 0,10 & $-2,11$ \\
\hline Cômoda & 214 & $0 \%$ & 0,08 & $-2,31$ \\
\hline \multicolumn{5}{|c|}{ Desvio $=193.628$ Graus de liberdade $=4$ Média 0,42} \\
\hline
\end{tabular}

\section{Síncope}

\begin{tabular}{lcccc}
\hline & $\begin{array}{c}\text { Frequência } \\
\text { de } \\
\text { Ocorrência }\end{array}$ & $\begin{array}{c}\text { Percentual } \\
\text { de } \\
\text { aplicação }\end{array}$ & $\begin{array}{c}\text { Peso } \\
\text { Relativo }\end{array}$ & Log-Odds \\
\hline Abóbora & 2.360 & $61 \%$ & 0,92 & 2,73 \\
Fósforo & 3.203 & $50 \%$ & 0,91 & 2,66 \\
Cócoras & 38 & $40 \%$ & 0,89 & 2,34 \\
Brócolis & 664 & $33 \%$ & 0,81 & 1,72 \\
Árvore & 18.569 & $15 \%$ & 0,59 & 0,60 \\
Horóscopo & 132 & $10 \%$ & 0,50 & 0,39 \\
Pérola & 585 & $0 \%$ & 0,19 & $-1,19$ \\
Ídolo & 3.980 & $0 \%$ & 0,18 & $-1,28$ \\
Cômoda & 214 & $0 \%$ & 0,16 & $-1,38$ \\
Agrícola & 56.420 & $0 \%$ & 0,16 & $-1,38$ \\
Símbolo & 7.88 & $0 \%$ & 0,16 & $-1,38$ \\
\hline \multicolumn{5}{c}{ Desvio } \\
\multicolumn{5}{c}{123.324 Graus de liberdade $=4$ Média 0,19} \\
\hline
\end{tabular}

Fonte: As autoras 
Com vistas a verificar o papel do léxico quanto à frequência de ocorrência dos itens lexicais na língua, realizamos uma divisão das palavras em dois grupos, com base na sua ocorrência por milhões no corpus do Português Brasileiro (LAEL/PUCSP). Para fazermos essa classificação, utilizamos a função Quartil disponível no software Excel, a qual, com base nos valores de frequência, realiza a divisão dos dados em quatro partes iguais e, a partir do valor do segundo quartil, valor central, permite-nos fazer a divisão dos dados. Das palavras apresentadas na Tabela 1, apresentada anteriormente, foram incluídas no primeiro grupo - grupo de palavras com baixa frequência - os itens lexicais pérola, horóscopo, cócoras, cômoda, brócolis e símbolo. No segundo grupo - grupo de palavras com alta frequência - foram incluídos os itens lexicais agrícola, árvore, fósforo, abóbora e ídolo.

A hipótese que guiou esta análise, com base na proposta do Modelo de Uso (BYBEE, 2002, 2010), é de que os itens lexicais mais frequentes são mais propensos a ser afetados pelos processos de variação. Nesse sentido, nossa conjectura é a de que os processos de síncope e alçamento atingem gradualmente as palavras, iniciando pelas formas mais frequentes e, paulatinamente, atingindo as palavras menos frequentes na língua. Na Gráfico 2 , a seguir, são apresentados os resultados quanto à ocorrência dos processos de síncope e alçamento de acordo com a frequência dos itens lexicais na língua.

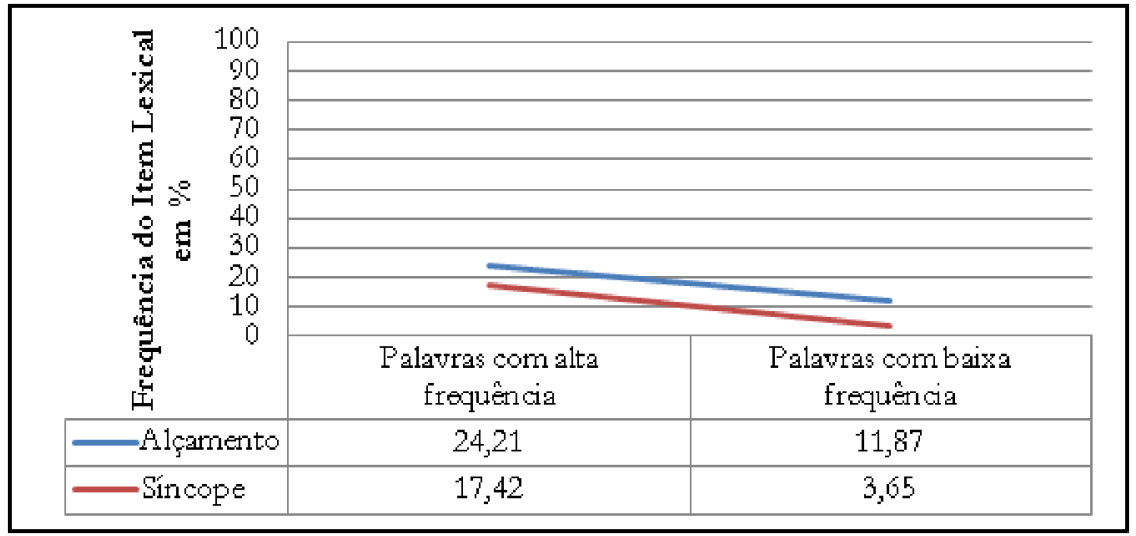

Fonte: As autoras

Gráfico 2 - Frequência do Item Lexical versus Alçamento e Síncope 
De acordo com os resultados, podemos observar que, em consonância com nossa hipótese, ambos os processos atingem preferencialmente as palavras mais frequentes na língua. O processo de alçamento apresenta média percentual de 24,21 (DP = 16,72) para as palavras com alta frequência e de $17,42(\mathrm{DP}=10,51)$ para as palavras com baixa frequência. Por sua vez, a síncope, mostra média percentual de $11,87(\mathrm{DP}=15,22)$ para as palavras mais frequentes e de 3,65 (DP = 6,40) para as palavras menos frequentes. Ou seja, quanto à frequência dos itens lexicais, os dois processos apresentam comportamento semelhante, e o alvo da variação parece ser as palavras mais frequentes na língua. Entretanto, quando testada a diferença entre os dois grupos, palavras frequentes e palavras pouco frequentes, por meio do software SPSS, versão $17.0^{7}$, os resultados, de acordo com o exposto na Tabela 2, a seguir, permitem comprovar diferença significativa somente com relação ao processo de síncope.

Tabela 2 - Frequência da Palavras versus Alçamento e Síncope

\begin{tabular}{|c|c|c|c|}
\hline \multicolumn{4}{|c|}{ Alçamento versus Frequência da Palavra } \\
\hline & $\begin{array}{c}\text { Média/ } \\
\text { Desvio Padrão }\end{array}$ & $\begin{array}{c}\text { Resultado Teste } \\
\text { T }\end{array}$ & $\underset{\text { (significância) }}{\mathrm{p}}$ \\
\hline $\begin{array}{l}\text { (a) mais } \\
\text { frequentes }\end{array}$ & $\begin{array}{c}24,21 \\
(\mathrm{DP}=16,72)\end{array}$ & & \\
\hline versus & & 1,356 & 0,198 \\
\hline $\begin{array}{l}\text { (b) menos } \\
\text { frequentes }\end{array}$ & $\begin{array}{c}17,42 \\
(\mathrm{DP}=10,51)\end{array}$ & & \\
\hline
\end{tabular}

7 A escolha de testes paramétricos ou não paramétricos foi realizada com base nos testes de normalidade Shapiro-Wilks e Kolmogorov-Smirnov: Quando se obteve valor de $p>0,05$ para os dois ou um dos testes, a escolha foi por aplicar testes paramétricos. 
Síncope versus Frequência da Palavra

\begin{tabular}{cccc}
\hline & $\begin{array}{c}\text { Média/ } \\
\text { Desvio Padrão }\end{array}$ & $\begin{array}{c}\text { Resultado Teste } \\
\text { Wilcoxon }(\mathbf{Z})\end{array}$ & $\begin{array}{c}\mathrm{p} \\
\text { (significância) }\end{array}$ \\
\hline $\begin{array}{c}\text { (a) mais } \\
\text { frequentes }\end{array}$ & 11,87 & & \\
versus & $\mathrm{DP}=15,22)$ & & \\
(b) menos & 3,65 & $-2,374$ & 0,018 \\
frequentes & $(\mathrm{DP}=6,40)$ & & \\
\hline
\end{tabular}

Fonte: As autoras

De acordo com os resultados descritos na Tabela 2, podemos inferir que o processo de síncope mostrou-se mais sensível à frequência das palavras do que o processo de alçamento, apresentando uma diferença significativa $(\mathrm{p}<0,05)$, entre palavras frequentes e palavras pouco frequentes. Embora essa diferença tenha sido verificada, tal constatação não nos permite fazer uma afirmação consistente quanto ao papel da frequência, visto que a maior manifestação do processo de apagamento, conforme já relatamos anteriormente, foi observada nos itens lexicais abóbora, fósforo, cócoras e brócolis. Dessas palavras, somente fósforo e abóbora apresentam alta frequência na língua. A mesma observação é válida para o processo de alçamento, quando se verifica que o fenômeno atinge tanto os itens lexicais frequentes, a exemplo de agrícola e ídolo, quanto os itens lexicais pouco frequentes, a exemplo de pérola e brócolis.

Nesse sentido, a frequência parece não ser o fator responsável pela escolha do falante por um dos processos. O fato de alguns itens lexicais mostrarem-se mais suscetíveis à aplicação da síncope ou à aplicação do alçamento, pela hipótese de que parte este estudo, pode estar, além de uma explicação linguística, relacionado a atuação de fatores de ordem social. Determinados itens lexicais podem estar mais fortemente cristalizados no léxico dos informantes com o alçamento, a preservação ou a síncope. Frente a isso, observamos uma relação dos processos com a forma mais reforçada 
para o falante em dado item lexical. Assim, explicaríamos o fato de que, em itens lexicais como cócoras e abóbora, a síncope, iniciada e facilitada por um contexto circundante, tende a ser a forma "predileta". Para esses itens lexicais, a redução por síncope está mais fortemente representada na memória do falante em relação à forma com o alçamento ou com a preservação da vogal /o/. Por outro lado, em itens lexicais como agrícola e ídolo, o alçamento é mais atuante em relação à síncope ou à preservação da vogal.

Não obstante, não se exclui o papel do léxico nos processos de síncope e de alçamento. O que entendemos é que os processos são desencadeados inicialmente por uma motivação estrutural, de ordem linguística, e que determinados itens lexicais, em virtude da alta recorrência de uma determinada forma, são registrados na memória do falante com a variante mais reforçada. Desse modo, entendemos, com base no Modelo de Uso (BYBEE, 2002, 2010) e na Teoria de Exemplares (PIERREHUMBERT, 2001, 2012), que o falante cria uma rede de associações entre palavras com estrutura semelhante e associa o detalhe fonético ao item lexical. Para itens lexicais como cócoras e abóbora, sugerimos que há um reforço da síncope em relação ao alçamento e à preservação. Nossos dados permitem corroborar essa hipótese ao verificar que o item lexical cócoras, por exemplo, é produzido por alguns falantes categoricamente como cróque, ou seja, essa forma se constitui como uma forma cristalizada.

Supomos, então, que fatores sociais desempenhem papel relevante na escolha dos sujeitos por uma das variantes em exame. Sabemos que há uma forte relação do fenômeno de síncope com a avaliação social: formas sincopadas tendem a ser estigmatizadas. A maior incidência do alçamento em relação à síncope em determinados itens lexicais poderia, dessa forma, ser atribuída à menor estigmatização desse fenômeno em relação à redução vocálica. Em outros termos, a manutenção da vogal postônica não final, seja pela preservação, seja pelo alçamento da vogal, resultaria em menor estigma na fala, conforme proposto por Santana (2012).

\subsection{As variáveis independentes extralinguísticas e os processos de síncope e de alçamento}

Entre as variáveis extralinguísticas consideradas como dimensão de análise por este estudo (Sexo, Faixa Etária e Escolaridade), apenas a Escolaridade 
mostrou relevância estatística tanto para o fenômeno de síncope quanto para o fenômeno de alçamento da vogal postônica não final /o/, corroborando os resultados percentuais obtidos por Chaves e Machry da Silva (no prelo). A Tabela 3 ilustra os resultados referentes ao processo de síncope para essa variável.

Tabela 3 - Escolaridade e Síncope

\begin{tabular}{lcccc}
\hline \multicolumn{1}{c}{ Fator } & $\begin{array}{c}\text { Síncope/ } \\
\text { Total de } \\
\text { tokens }\end{array}$ & $\begin{array}{c}\text { Aplicação } \\
\mathbf{( \% )}\end{array}$ & $\begin{array}{c}\text { Peso } \\
\text { Relativo }\end{array}$ & Log-odd \\
\hline Ensino Fundamental & $19 / 74$ & $25,7 \%$ & 0,81 & 1,444 \\
Ensino Médio & $10 / 70$ & $14,3 \%$ & 0,47 & $-0,0116$ \\
Ensino Superior & $6 / 34$ & $17,6 \%$ & 0,21 & $-1,326$ \\
\hline
\end{tabular}

Fonte: As autoras

Conforme apontam os resultados expressos na Tabela 3, no grupo dos informantes com escolaridade mais baixa (Ensino Fundamental) foi computado o maior percentual de ocorrência de síncope, equivalente a 25,7\% dos dados. Após computação estatística dos dados pelo programa Rbrul, esse grupo também foi o único a apresentar pesos probabilísticos de realização de síncope relevantes (Peso Relativo $=0,81, \log$-odd $=1,444$ ). Tal resultado vai ao encontro da maior parte dos estudos relativos ao apagamento da vogal postônica não final em dados do PB (Cf. Seção 1), nos quais, em geral, os sujeitos com menor grau de instrução também são apontados como aqueles que realizam a síncope com mais frequência.

Em relação ao processo de alçamento, observamos, nos dados em exame, uma tendência oposta: o grupo de informantes com maior grau de instrução foi apontado como aquele que influenciou de forma mais significativa a ocorrência do alçamento. Os valores relativos a cada um dos fatores que compõem essa variável encontram-se expostos a seguir. 
Tabela 4 - Escolaridade e Alçamento

\begin{tabular}{lcccc}
\hline \multicolumn{1}{c}{ Fator } & $\begin{array}{c}\text { Alçamento/ } \\
\text { Total de } \\
\text { tokens }\end{array}$ & $\begin{array}{c}\text { Aplicação } \\
\mathbf{( \% )}\end{array}$ & $\begin{array}{c}\text { Peso } \\
\text { Relativo }\end{array}$ & Log-odd \\
\hline Ensino Superior & $22 / 34$ & $64,7 \%$ & 0,75 & 1,084 \\
Ensino Médio & $28 / 70$ & $40 \%$ & 0,49 & $-0,012$ \\
Ensino Fundamental & $24 / 74$ & $32,4 \%$ & 0,25 & $-1,072$ \\
\hline
\end{tabular}

Fonte: As autoras

Conforme indica a Tabela 4, os informantes com Ensino Superior aplicaram o processo de alçamento em $64,7 \%$ dos dados. Essa mesma tendência pôde ser verificada também nos valores do peso relativo $(0,75)$ e do Log-odd (1.084). Sendo assim, verificamos uma relação entre o grau de instrução dos falantes e a atuação do processo de alçamento da vogal postônica não final /o/.

A fim de visualizarmos melhor os resultados apresentados, o Gráfico 3, a seguir, com base nos pesos relativos extraídos de cada uma das rodadas, busca estabelecer uma relação entre ambos os fenômenos.

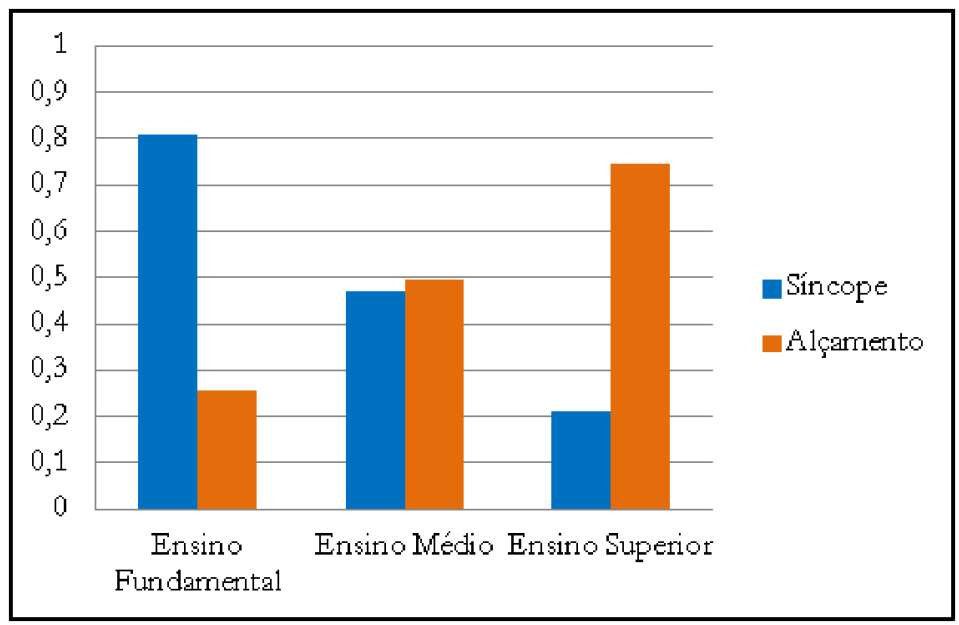

Fonte: As autoras

Gráfico 3 - Cruzamento entre os fenômenos de síncope e alçamento e a variável Escolaridade 
Com base no Gráfico 3, é possível vislumbrar que, à medida que a escolaridade dos sujeitos aumenta, o alçamento passa a ser empregado também com maior frequência. Por outro lado, os valores de aplicação da síncope, verificada em maior proporção no grupo de informantes com escolaridade equivalente ao Ensino Fundamental, decrescem em direção aos sujeitos mais instruídos.

Assim como já identificamos em estudo prévio (CHAVES; MACHRY DA SILVA, no prelo), ao realizarmos a análise por informantes, torna-se evidente que, conforme aumenta a escolaridade, os indivíduos passam a aplicar, com maior frequência, a regra de alçamento vocálico, como ilustra o Gráfico 4, que apresenta os índices de aplicação de síncope e de alçamento para cada um dos informantes, organizados, no gráfico, em relação ao grau de escolaridade (ascendente).

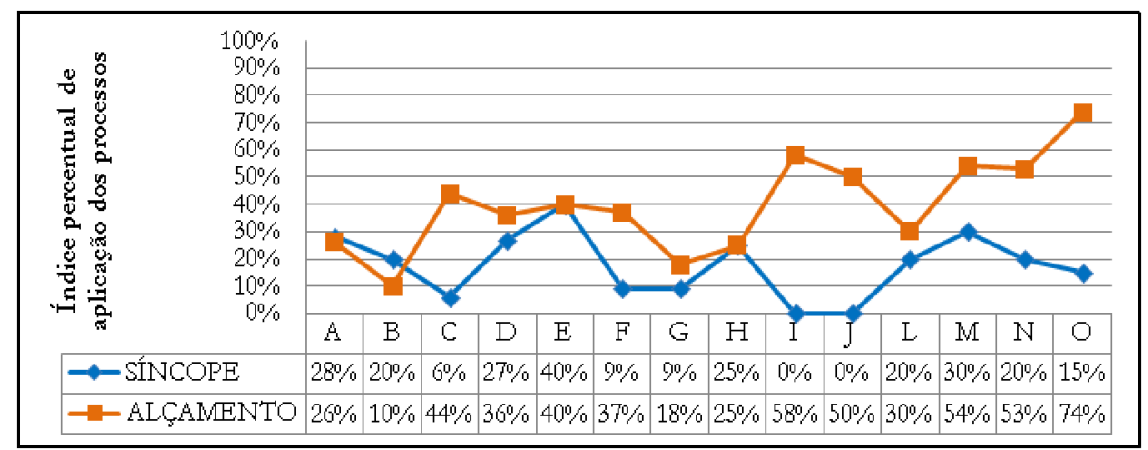

Fonte: Adaptado de Chaves e Machry da Silva (no prelo).

Gráfico 4 - Aplicação de síncope e alçamento da vogal postônica não final /o/ por informante

Nos dados provenientes da fala de sujeitos com menor grau de instrução, equivalente até a $8^{a}$ série do Ensino Fundamental (informante $\mathrm{A}$ ao informante $\mathrm{F}$ ), verificamos a aplicação de ambos os fenômenos: os informantes A, B, D e E apresentaram taxas próximas de aplicação de síncope e de alçamento, enquanto os informantes $\mathrm{C}$ e $\mathrm{F}$ apresentaram índices mais distantes. No que tange aos dados dos indivíduos com Ensino Médio (informante $\mathrm{G}$ ao informante $\mathrm{M}$ ), observamos uma prevalência do alçamento 
em relação à síncope - apenas o informante $\mathrm{H}$ apresenta, em sua fala, os mesmos percentuais de realização dos fenômenos. A "preferência" pelo alçamento é vislumbrada, de forma mais acentuada, na fala dos dois sujeitos com maior grau de escolaridade, correspondente ao Ensino Superior.

A partir desses resultados, buscamos verificar se haveria uma correlação negativa entre os fenômenos (síncope e alçamento) em relação à variável escolaridade. Para isso, fizemos uso do teste de correlação Kendall Tau - teste aplicado em dados não paramétricos, no software estatístico SPSS (versão 17). Essa análise foi conduzida com base nos pesos relativos apresentados, por cada fenômeno variável, para cada um dos níveis de escolaridade. Confirmando a hipótese inicial, verificamos uma correlação negativa $(\mathrm{P}<0.01)$ entre ambos os processos: conforme ilustra o gráfico a seguir.

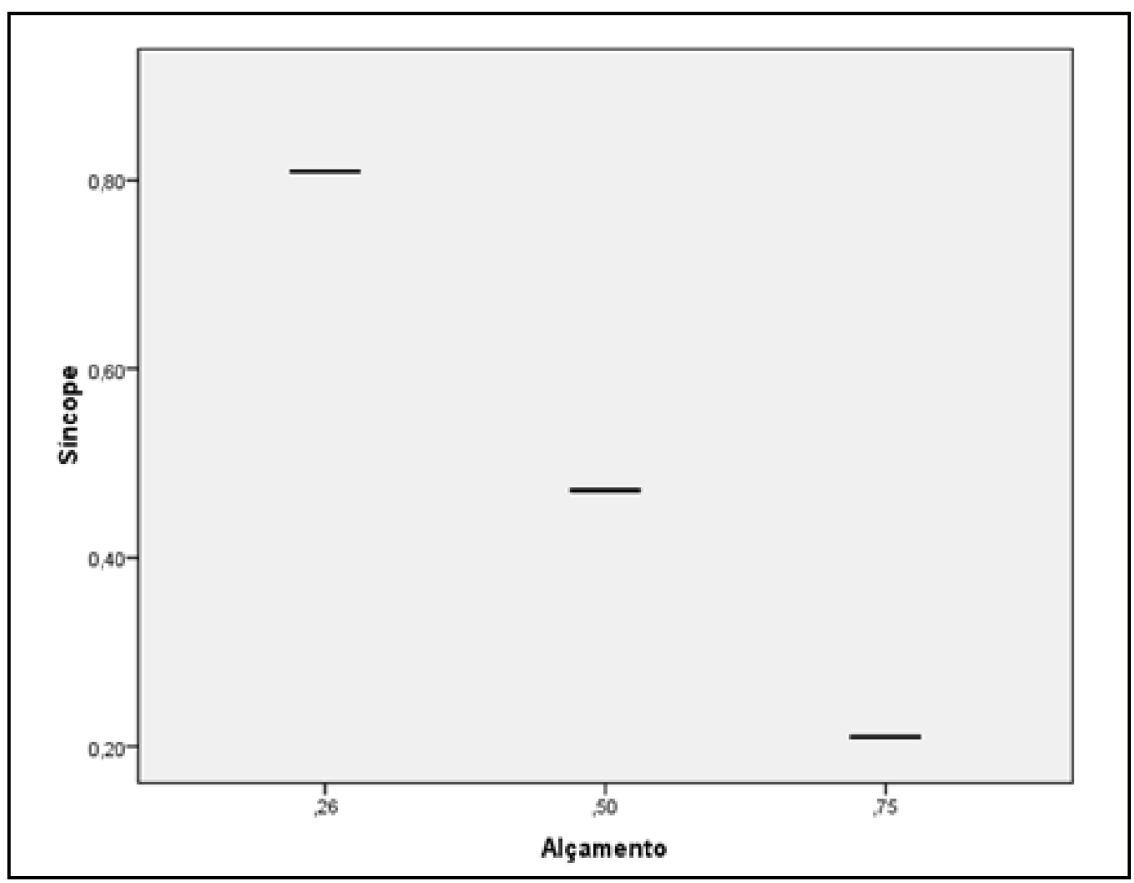

Fonte: As autoras

Gráfico 5 - Análise de correlação entre a produção síncope e alçamento nos três níveis de escolaridade 
Os resultados ilustrados pelo Gráfico 5 confirmam, como os estudos sobre o apagamento das vogais postônicas não finais têm afirmado, que a síncope parece ser um fenômeno estigmatizado na língua portuguesa e, concomitantemente, parece indicar que há alguma noção de prestígio agregada ao processo de alçamento. Diante disso, discutimos, na próxima seção, como os dois processos se encaixam na matriz linguística e social (problema do encaixamento) na comunidade.

\subsection{O problema do encaixamento e os processos de síncope e de alçamento}

O problema do encaixamento, conforme apresentado pela primeira vez por Weinreich, Labov e Herzog (1968), trata de como as mudanças e, no caso deste artigo, os processos em variação, encontram-se acomodados tanto na estrutura linguística como na estrutura social.

Com base na análise desenvolvida neste estudo, podemos afirmar que, no que concerne ao problema do encaixamento linguístico: (i) ambos os fenômenos variáveis investigados são suscetíveis à aplicação em contextos semelhantes; (ii) a frequência lexical não parece ser o que impulsiona inicialmente a ocorrência das formas variantes, embora palavras mais frequentes sejam mais propícias a sofrer variação (tanto por síncope quanto por alçamento); (iii) há indícios de que, com a forma variante impulsionada por uma motivação contextual, alguns itens lexicais passam a ser "cristalizados" pelo indivíduo, de acordo com sua escolaridade, de uma ou outra forma (preservação, alçamento ou síncope da vogal postônica não final $/ \mathrm{o} /$ ).

Já no que tange ao encaixamento na matriz social, podemos ressaltar que: (i) a Escolaridade desempenha papel para ambos os fenômenos, entretanto, numa direção oposta - informantes mais escolarizados realizam mais alçamento e menos síncope, e informantes menos escolarizados, o oposto, mais síncope e menos alçamento; (ii) há uma correlação negativa entre os fenômenos, o que indica que nesses contextos parece haver uma distribuição complementar da aplicação dos fenômenos relacionada diretamente ao grau de escolaridade dos informantes - fato também verificado na análise por indivíduo. 


\section{Considerações Finais}

Nesse artigo, propomos estabelecer uma relação entre dois processos possíveis de incidir sobre a vogal média /o/ em posição postônica não final: o de sincope e o de alçamento. No que diz respeito aos objetivos delimitados no princípio da presente pesquisa, verifica-se que: (i) os processos, assim como relatam estudos precedentes, manifestam-se em ambientes linguísticos semelhantes; (ii) as variáveis Item Lexical e Escolaridade desempenham papel significativo na aplicação de ambos os fenômenos; (iii) no que se refere especificamente à Escolaridade, verificamos que, à medida que a escolaridade aumenta, a produção de síncope (fenômeno estigmatizado) diminui e, de forma distinta, a produção de alçamento se torna mais elevada, configurando, portanto, uma correlação negativa entre os processos.

O presente estudo, portanto, apresenta indícios de que a escolha do processo de síncope ou de alçamento apresenta semelhança quanto à atuação dos fatores linguísticos, mas, em um segundo momento, as formas variantes espalham-se pelo léxico de forma independente. Verificamos, nesse processo, que a escolha do falante por um ou outro fenômeno, além do item lexical, está relacionada também com o grau de instrução dos falantes: sujeitos com menor grau de instrução tendem a ter, para alguns itens lexicais, a forma sincopada cristalizada, o que não se verifica em falantes com maior grau de instrução. Por conseguinte, os dados investigados por esse estudo apresentam pistas de como tais fenômenos, síncope e alçamento, estão encaixados na matriz de concomitantes linguísticos e sociais da variedade em exame.

\section{Referências}

AMARAL, M. P. do. As proparoxitonas: teoria e variação. 1999. Tese (Doutorado em Letras) - Pontifícia Universidade Católica do Rio Grande do Sul. Porto Alegre.

BYBEE, J. Phonology and language use. Cambridge: Cambridge University Press, 2002. 
BYBEE, J. Language, usage and cognition. New York: Cambridge University Press, 2010.

CHAVES, R. G. A redução de proparoxitonos na fala do Sul do Brasil. 2011. Dissertação (Mestrado em Letras) - Pontifícia Universidade Católica do Rio Grande do Sul, Porto Alegre.

CHAVES, R. G.; MACHRY DA SILVA, S. Sincope e alçamento da vogal postônica não final /o/: indícios de motivação extralinguística. Working Papers. (no prelo).

GUY, G. The cognitive coherence of sociolects: How do speakers handle multiple sociolinguistic variables? Journal of Pragmatics, v. 52, p. 63-71, Jun. 2013.

JOHNSON, D. Getting off the GoldVarb standard: Introducing Rbrul for mixed-effects variable rule analysis. Language and Linguistics Compass, v. 3, n. 1, p. 359-383, 2009.

LABOV, W. Sociolinguistic patterns. Philadelphia: University Pennsylvania Press, 1972.

LABOV, W. Principles of linguistic change: Internal factors. Cambridge: Blackwell, 1994.

LABOV, W. Principles of linguistic change: Social factors. Cambridge: Blackwell, 2001.

LABOV, W. Principles of linguistic change: Cognitive and cultural factors. Cambridge: Wiley-Blackwell, 2010.

LIMA, G. de O. O efeito da síncope de proparoxitonas: análise fonológica e variacionista com dados do sudoeste goiano. 2008. Dissertação (Mestrado em Estudos Linguísticos) - Universidade Federal de Uberlândia, Uberlândia. 
MACHRY DA SILVA, S. Elevação das vogais médias átonas finais e não finais no português falado em Rincão Vermelho - RS. 2009. Dissertação (Mestrado em Letras) - Pontifícia Universidade Católica do Rio Grande do Sul. Porto Alegre.

PIERREHUMBERT, J. B. Exemplar dynamics: Word frequency, lenition, and contrast. In.: BYBEE, J.; HOPPER, P. Frequency effects and the emergence of linguistic structure. Amsterdam: John Benjamin, 2001. p. 137-157.

PIERREHUMBERT, J. B. The dynamic lexicon. In.: COHN, A.; FOUGERON, C.; HUFFMAN, M. The oxford handbook of laboratory phonology. Oxford University Press, 2012. p. 173-183.

RAMOS, A. P. Descrições das vogais postônicas na variedade do noroeste paulista. 2009. Dissertação (Mestrado em Estudos Linguísticos) - Universidade Estadual Paulista, São José do Rio Preto.

SANTANA, A. P. A síncope revisitada: análise com base no corpus do ALIMA. Littera Online, n. 5, v. 3, p. 50-68, 2012. Disponível em: < http:// migre.me/qJExZ>. Acesso em: 13 set. 2014.

SANKOFF, D. Unpublished program and documentation. 1975.

SANKOFF, D.; TAGLIAMONTE, S.; SMITH, E. Goldvarb X: a variable rule application for Macintosh and Windows. 2005. Disponível em: <http://migre.me/qJED8>.

SCHMITT, C. J. Redução vocálica postônica e estrutura prosódica. 1987.

Dissertação (Mestrado em Letras) - Pontifícia Universidade Católica do Rio Grande do Sul, Porto Alegre.

SILVA, A. P. da. Supressão da vogal postônica não final: uma tendência das proparoxítonas na Língua Portuguesa com evidências no falar sapeense. 2006. Dissertação (Mestrado em Letras) - Universidade Federal da Paraíba, João Pessoa. 
VIEIRA, M. J. B. Neutralizaçãa das vogais médias postônicas. 1994. Dissertação (Mestrado em Letras) - Pontifícia Universidade Católica do Rio Grande do Sul, Porto Alegre.

VIEIRA, M. J. B. As vogais médias postônicas: uma análise variacionista. In: BISOL, L.; BRESCANCINI, C. (Orgs.) Fonologia e variação: recortes do português brasileiro.Porto Alegre: EDIPUCRS, 2002. p. 127-159.

WEINREICH, U.; LABOV, W.; HERZOG, M. Empirical foundations for a theory of language change. In: LEHMANN, W.; MALKIEL, Y. (Eds.). Directions for Historical Linguistics. Austin: University of Texas Press, 1968. p. 95-195.

Recebido em: 20/11/2014 Aceito: 21/04/2015 